\title{
Static internal combustion engine operating states in vehicle driving tests
}

The article presents the compression-ignition engine test results of static operating states in driving tests: NEDC (New European Driving Cycle), RDE (Real Driving Emissions) and the Malta custom test cycle, developed at the Poznan University of Technology. The NEDC and Malta tests were carried out as drive cycle simulations on the engine test bench, the RDE test was carried out in the real driving conditions. The engine operating states are described by the physical quantities of speed and torque. For each of the tests, zero-dimensional characteristics of the values describing the engine operation states were determined, including: mean value and average standard deviation and coefficient of variation. Histograms of quantities describing the engine's operating states for considered tests and driving conditions were also determined. A large diversity of zero-dimensional characteristics of the quantities describing the engine's operating states for the considered driving tests and driving conditions was found.

Key words: combustion engines, drive tests, engine operating conditions

\section{Introduction}

The knowledge gap about the usable properties of internal combustion engines in their real operating conditions means that the results of tests that are only compatible with the type approval procedures are no longer sufficient. The functional properties of internal combustion engines, determined in approval procedures, are in fact significant for the tested objects only under the conditions of these procedures [4] - in other conditions these properties can vary considerably [3, 4], and for this reason such a great attention is paid to engine control algorithms [8]. The functional properties of internal combustion engines, which are particularly strongly dependent on the operating conditions of the engines, both static and - most of all - dynamic, are the values characterizing the exhaust emission [3, 4] and, to a lesser degree, fuel consumption. In order to assess the exhaust emission in conditions deviating from the conditions of type approval procedures, and additionally burdened with a certain uncertainty of accidental processes, the tests of car engines in real operating conditions were introduced. The Real Driving Emissions (RDE) [6,7] procedure allows the study of exhaust emissions from a car engine through the use of Portable Emissions Measurement System (PEMS). The procedure for selecting the speed curve in the RDE test is defined in the regulations in a very precise and restrictive way $[1,6,7]$. Nevertheless, there is a significant margin of indeterminacy in the vehicle speed, which means that this process can be treated as random $[3,4]$. The specific realizations of this process, which are the speed curves of the vehicle used in research, may differ significantly from the speed curves in official type approval procedures. Therefore, the task was undertaken to investigate these differences. The tests were performed for the engine's operating states, determined by the vehicle speed. Engine states selected for testing were determined by the NEDC test [9], the Malta test [1], which simulated the NEDC test in road conditions, and states registered in one of the actual RDE tests. The tests were carried out for the same test object. The subject of the research were static states of combustion engine operation, corresponding to dynamic states in real engine operation conditions.

\section{Research aim and objects}

The aim of the research was to assess the static operating states of a combustion engine vehicle in conditions corresponding to its real operation. To do this, the results of tests in both real conditions as well as on the engine dynamometer were used. Real-world tests were conducted in accordance with the RDE procedure. On the engine test bench, NEDC tests and the Malta test were carried out, developed at the Poznan University of Technology to simulate the NEDC test in road conditions.

The test objects were: an engine and a car equipped with the same engine. The engine tested was a Fiat 1.3 JTD (MultiJet) 4-cylinder compression-ignition engine with a turbocharged displacement of $1.3 \mathrm{dm}^{3}$, Euro 4 exhaust emission class. The tested vehicle was a Fiat Idea passenger car with a mileage of $92,000 \mathrm{~km}$.

The Dynoroad $120 \mathrm{~kW}$ AVL engine dynamometer station was used to test the engine. Road tests were conducted using the PEMS apparatus. Measurement values in dynamic conditions were recorded at a frequency of $10 \mathrm{~Hz}$.

Research objects and test equipment were described in detail in $[1,2]$.

\section{Empirical test results}

Figures 1-3 show the engine speed trends in research tests. Figures 4-6 show the relative torque curves. The relative torque has been defined in relation to the torque at the full engine control setting, i.e. under conditions corresponding to the maximum power characteristics of the engine. The relative torque is:

$$
M_{e r}(n)=\frac{M_{e}(n)}{M_{e \max }(n)}
$$

where: $M_{e}(n)$ - torque at engine speed $n, M_{e \max }(n)-$ maximum torque at engine speed $n, n-$ engine speed. 


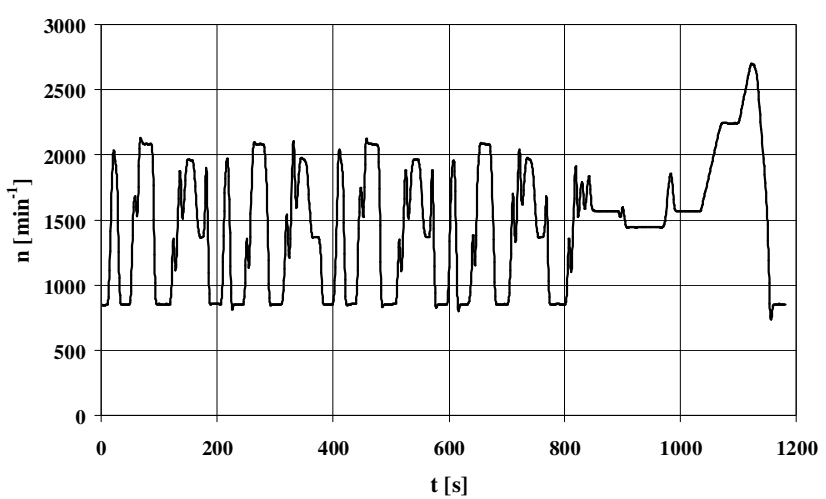

Fig. 1. Engine speed characteristic in the NEDC test

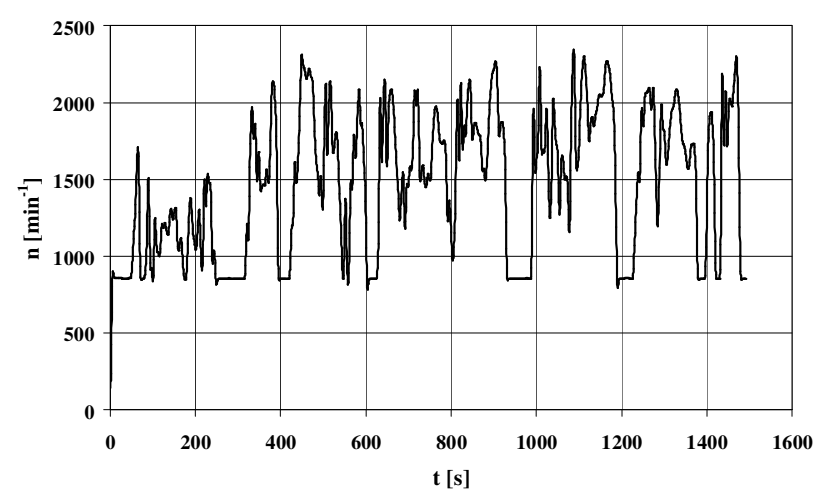

Fig. 2. Engine speed characteristic in the Malta test

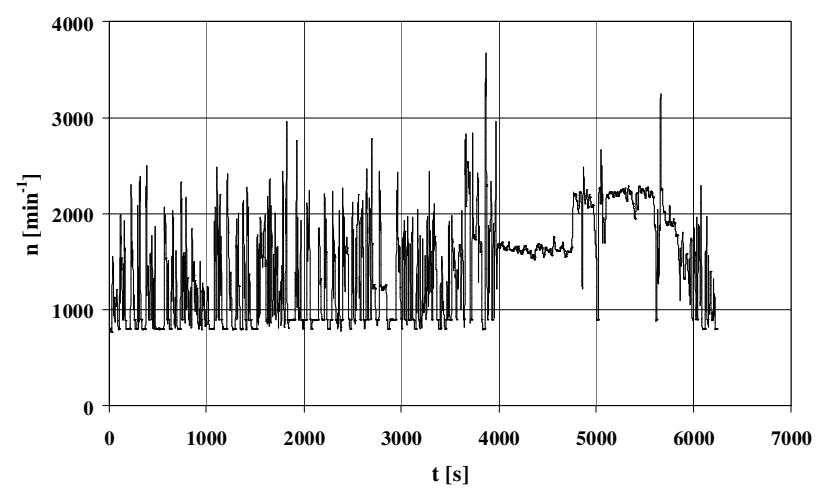

Fig. 3. Engine speed characteristic in the RDE test

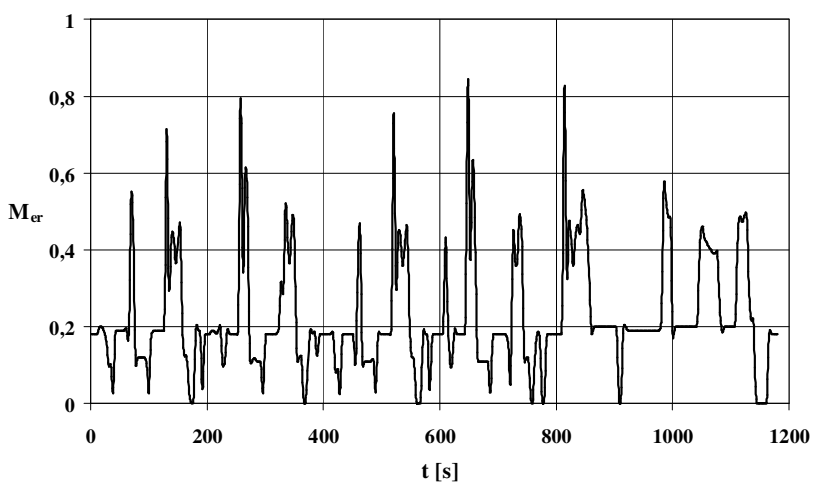

Fig. 4. The relative torque characteristic in the NEDC test

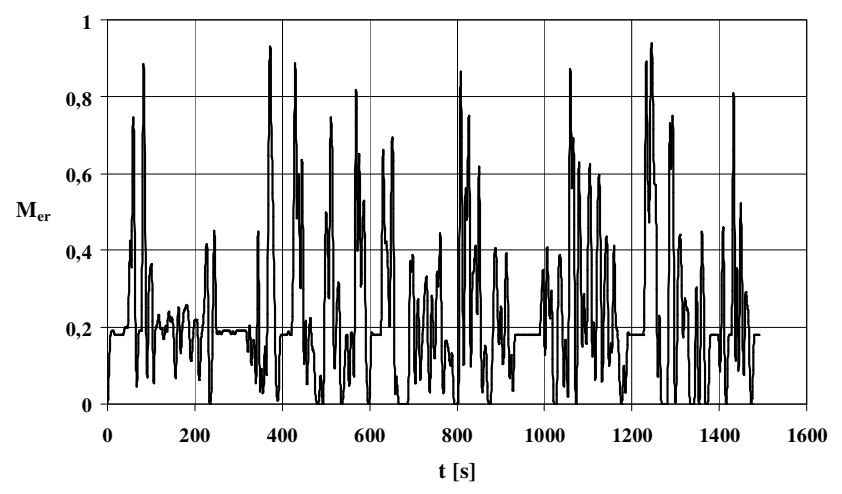

Fig. 5. The relative torque characteristic in the Malta test

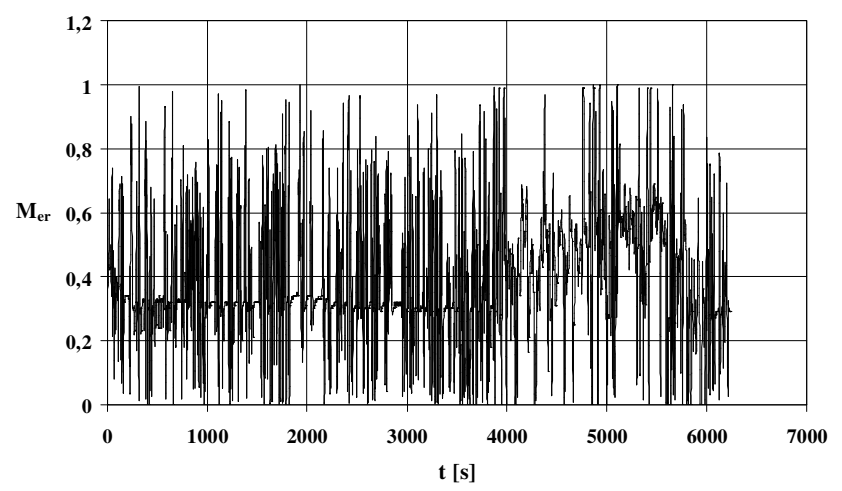

Fig. 6. The relative torque characteristic in the RDE test

The duration of NEDC and Malta tests are similar, while the RDE test lasts 4-5 times longer. The Malta test was developed at the Poznan University of Technology in order to simulate road conditions of the NEDC test, but the fundamental difference in the properties of both tests results from the method of their creation. The NEDC test is created in accordance with the principle of similarity of zero-dimensional characteristics, primarily the vehicle speed, while the Malta test was created based on an accurate simulation of the vehicle speed characteristic in the time domain [5]. This is due to the stronger dynamic properties of the Malta test, but this is not the subject of this work.

\section{Analysis of an internal combustion engine operating states}

Figures 7-9 present the results of static states corresponding to dynamic states in the empirical research tests. The results are shown in the coordinates of the engine rotational speed - relative torque.

There are significant similarities between the NEDC and Malta tests due to the zero-dimensional characteristics shown in Figures 10-13.

In the case of engine rotational speed, the similarity of characteristics is significant, both the mean value (Fig. 10) and the coefficient of variation (Fig. 11).

In the case of engine load there is a large similarity between the average relative torque value for NEDC and Malta tests, while the average engine load in the RDE test is much larger (Fig. 12). 


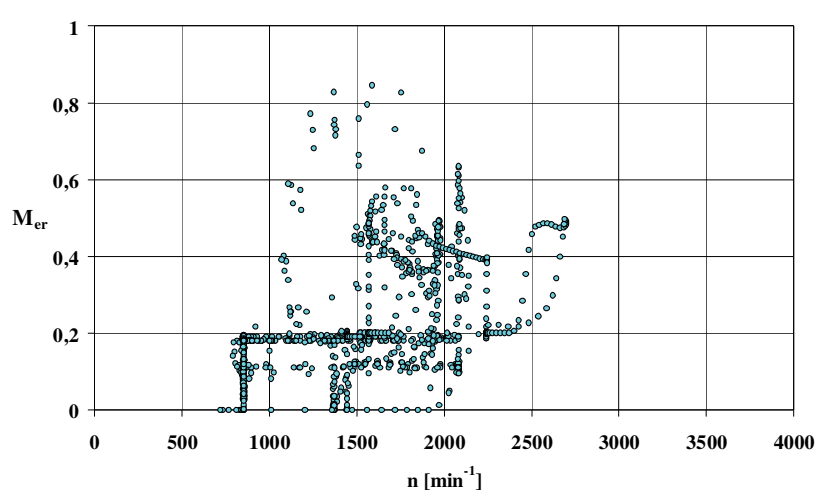

Fig. 7. A set of points in coordinates of engine rotational speed-relative torque in the NEDC test

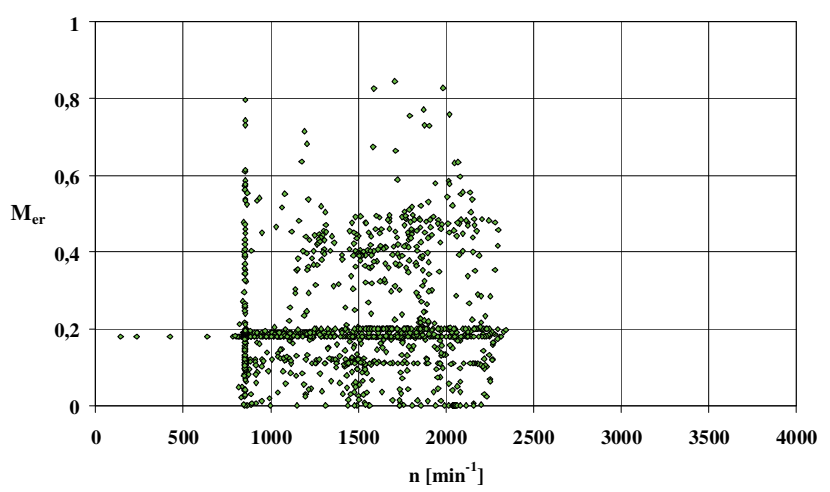

Fig. 8. A set of points in coordinates of engine rotational speed-relative torque in the Malta test

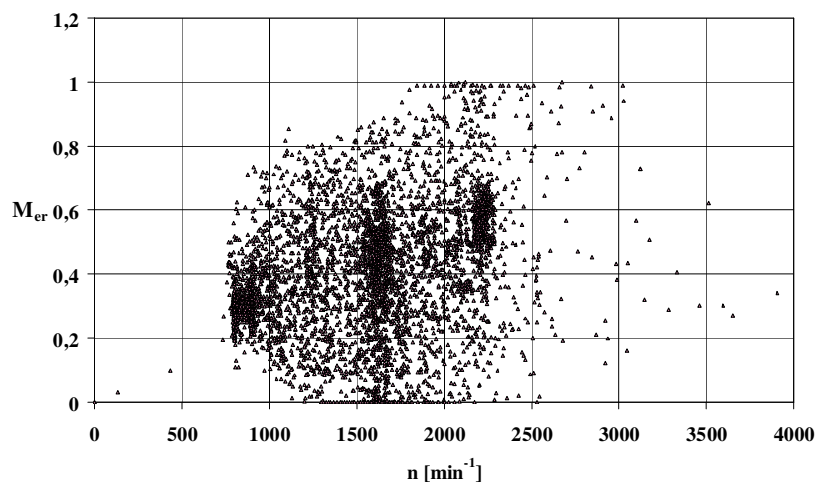

Fig. 9. A set of points in coordinates of engine rotational speed-relative torque in the RDE test

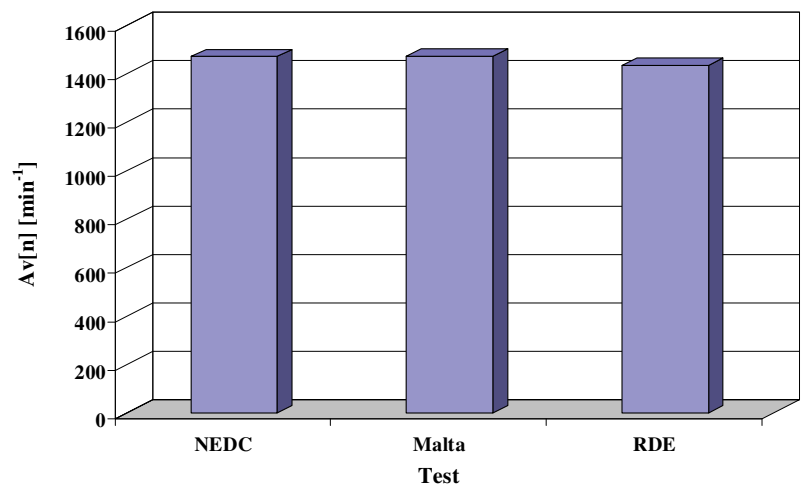

Fig. 10. Average engine speed value in NEDC, Malta and RDE tests

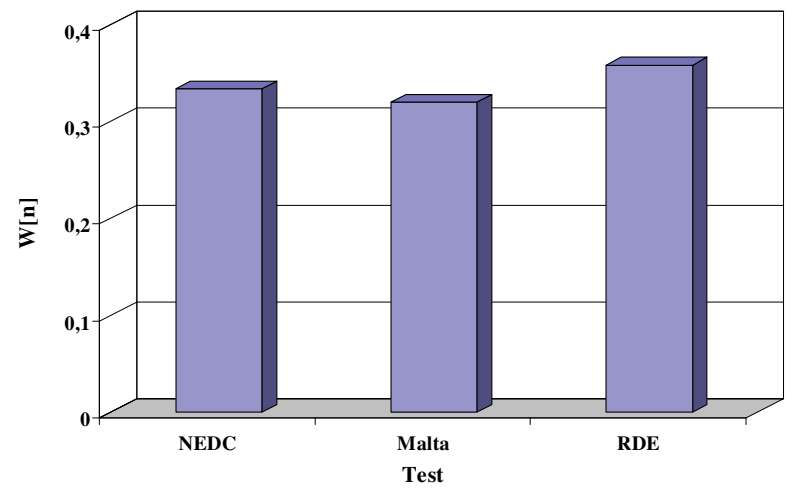

Fig. 11. Coefficient of variation of rotational speed in NEDC, Malta and RDE tests

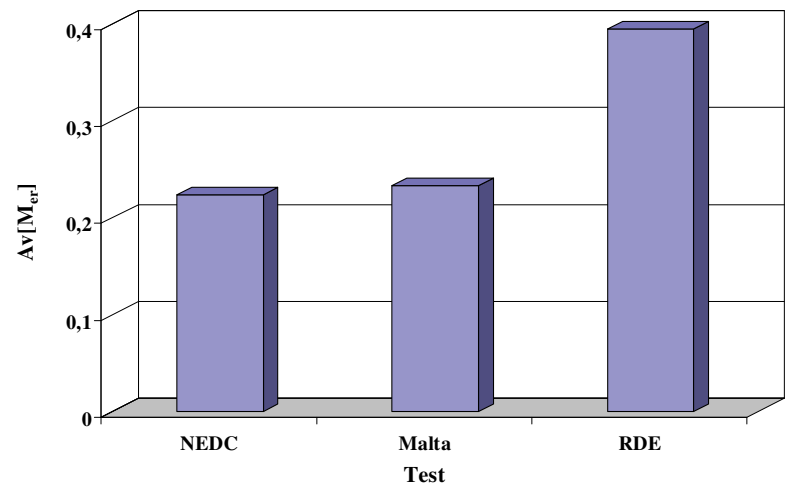

Fig. 12. Mean relative torque value in NEDC, Malta and RDE tests

It is also significant that the coefficient of variation of the relative torque reached the highest values for the Malta test (Fig. 13).

Figures 14 and 15 present the analysis results of the mean value and the coefficient of variation for the relative engine power. Relative engine power is defined as the product of relative torque and relative engine speed compared to the rated speed:

$$
\mathrm{N}_{\mathrm{er}}(\mathrm{n})=\mathrm{M}_{\mathrm{er}}(\mathrm{n}) \cdot \frac{\mathrm{n}}{\mathrm{n}_{\mathrm{N}}}
$$

where: $\mathrm{M}_{\mathrm{er}}$ - relative torque, $\mathrm{n}-$ engine speed, $\mathrm{n}_{\mathrm{N}}$ - rated engine speed.

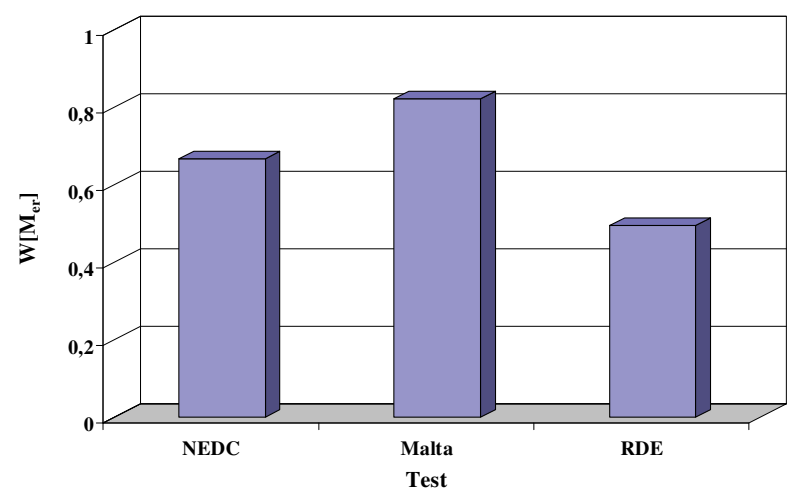

Fig. 13. The relative torque variation coefficient in the NEDC, Malta and RDE tests 


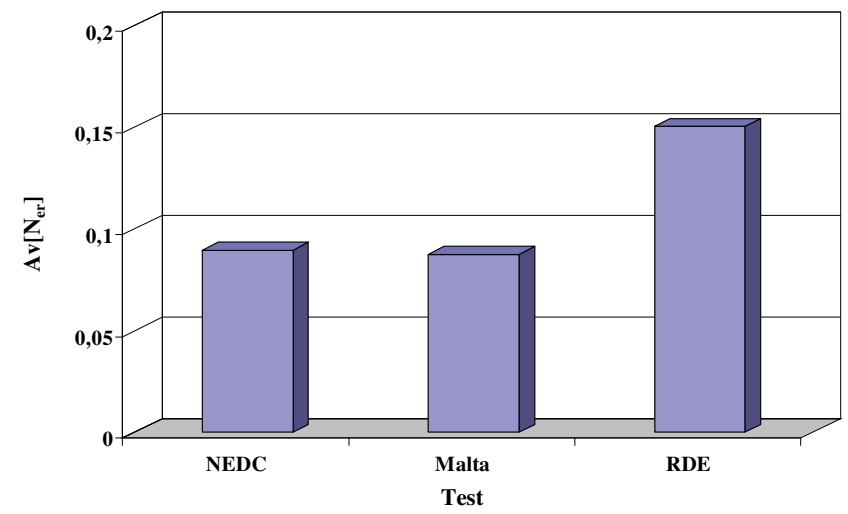

Fig. 14. The average value of the relative engine power in the NEDC, Malta and RDE tests

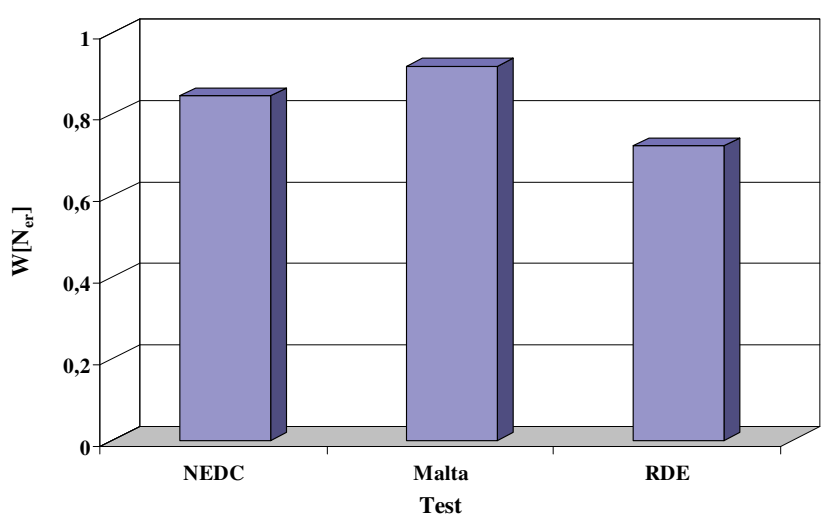

Fig. 15. The relative engine power variation coefficient in the NEDC, Malta and RDE tests

The average value of the relative engine power is almost twice as high for the RDE test compared to the other tests (Fig. 14). At the same time, the RDE test has the smallest coefficient of relative power variation (Fig. 15).

Figure 16 shows the set of average engine speed values and the relative torque in the NEDC, Malta and RDE tests as a function of rotational speed - relative torque, while in Figure 17 - the set of average engine speed values and the average relative engine power values in the coordinates of rotational speed - relative power.

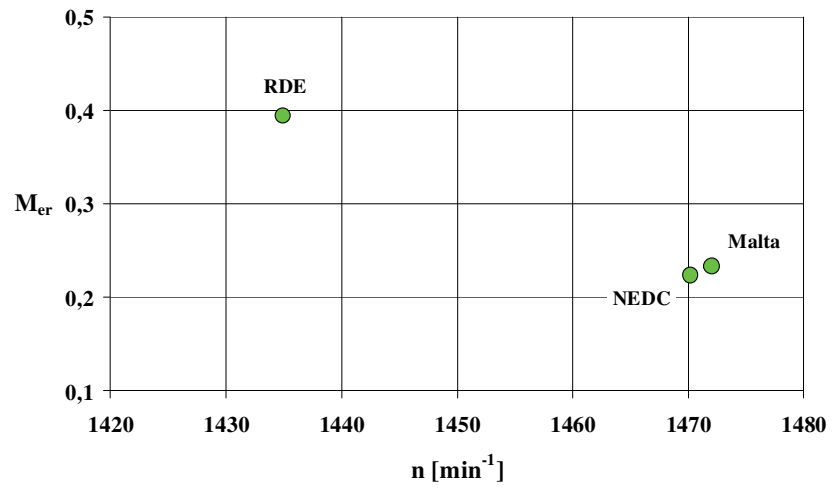

Fig. 16. A set of average engine speed points and an average relative torque value in coordinates: rotational speed-relative torque in NEDC, Malta and RDE tests

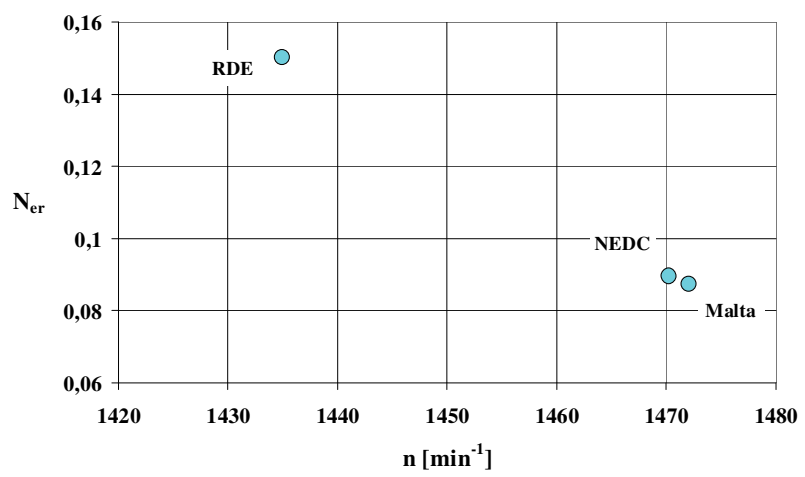

Fig. 17. Collection of points of average engine speed value and average value of relative engine power in coordinates of rotational speed-relative power in NEDC, Malta and RDE tests

It is clearly visible that for the NEDC and Malta tests the average values of the rotational speed, relative torque and - as a consequence of the relative engine power - are close to each other. In the RDE test, the quantities that characterize the engine load are almost twice as large.

Figures 18-20 show the relative number of occurrences of: speed, relative torque and relative power engine states in the analyzed tests.

The relative number of occurrences in the histogram is

$$
\mathrm{h}=\frac{\mathrm{H}}{\mathrm{L}}
$$

where: $\mathrm{H}$ - the number of elements of the set within the counting interval, L - set size (number of elements of the set).

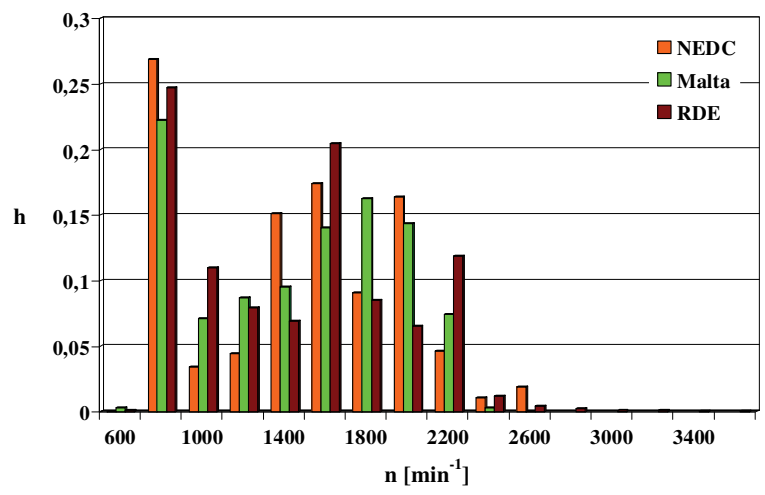

Fig. 18. Engine speed histogram in NEDC, Malta and RDE tests

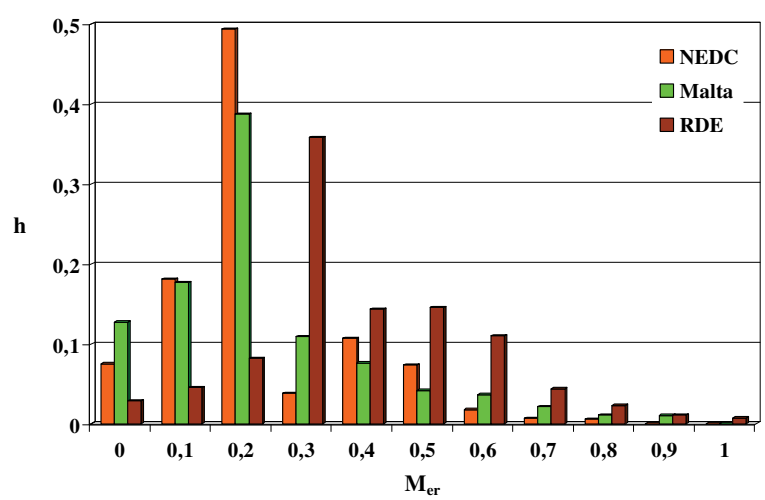

Fig. 19. Histogram of relative torque in NEDC, Malta and RDE tests 


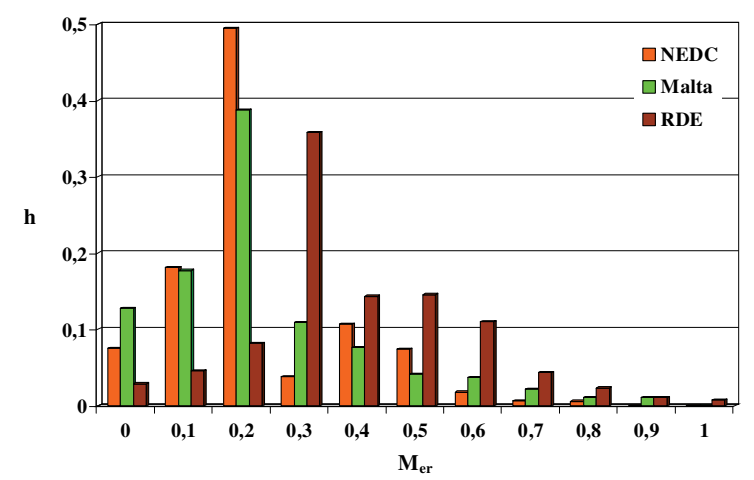

Fig. 20. Histogram of relative engine power in the NEDC, Malta and RDE tests

The process value results also confirmed the conclusions drawn from the assessment of the average value and the coefficient of variation. For rotational speed, the differences in histograms for individual tests are not significant, while for the relative torque and relative engine power much higher relative values were found in the RDE test with the increased occurrence of states with high values compared to the other tests.

\section{Conclusions}

The analysis of the internal combustion engine static operating states, corresponding to the operating conditions of the engine under dynamic conditions in drive tests, was carried out for the characteristics of zero-dimensional processes characterizing the engine operation status and in the field of values of these processes. The analyzed processes and values of the engine's operating states were: rotational speed, relative torque and relative engine power. The zero-dimensional characteristics of the processes studied were: mean value and coefficient of variation. In the field of process values, histograms were analyzed.

Based on the static operating states analysis of the internal combustion engine, the following conclusion can be drawn: there is a large similarity between the analyzed characteristics for NEDC and Malta tests, while the RDE test is distinguished by a significantly higher engine load. Therefore, it can be concluded from the analysis of static states of engine operation that conditions in the RDE test favor the increased emission of nitrogen oxides. Of course, the results of the pollutant, which is averaged throughout the road emissions tests, are also influenced by the dynamic conditions of engine operation $[1,3,4]$.

\section{Bibliography}

[1] ANDRYCH-ZALEWSKA, M., CHŁOPEK, Z., MERKISZ, J., PIELECHA, J. Evaluation of the test drive cycle conditions impact on exhaust emissions from an internal combustion engine. Combustion Engines. 2018, 175(4), 3-9.

[2] ANDRYCH-ZALEWSKA, M. Wpływ katalizatora wewnętrznego na emisję spalin w stanach pracy silnika o zapłonie samoczynnym odpowiadających jego użytkowaniu trakcyjnemu. Rozprawa doktorska. Poznań 2018.

[3] CHŁOPEK, Z. Modelowanie procesów emisji spalin w warunkach eksploatacji trakcyjnej silników spalinowych. „Mechanika" z. 173. Oficyna Wydawnicza Politechniki Warszawskiej. Warszawa 1999.

[4] CHŁOPEK, Z. Some remarks on engine testing in dynamic states. Silniki Spalinowe-Combustion Engines. 2010, 4(143), 60-72.

[5] CHŁOPEK, Z. Synthesis of driving cycles in accordance with the criterion of similarity of frequency characteristics.

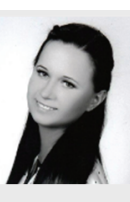

Prof. Zdzisław Chłopek, DSc. DEng. - Faculty of Automotive and Construction Machinery Engineering, Warsaw University of Technology.

e-mail: zdzislaw.chlopek@pw.edu.pl
Eksploatacja i Niezawodnosc - Maintenance and Reliability. 2016, 18(4), 572-577.

[6] Commission Regulation (EU) 2016/427 of 10 March 2016 amending Regulation (EC) No. 692/2008 as regards emissions from light passenger and commercial vehicles (Euro 6), Verifying Real Driving Emissions, Official J. European Union, L 82, 2016.

[7] Commission Regulation (EU) 2016/646 of 20 April 2016 amending Regulation (EC) No. 692/2008 as regards emissions from light passenger and commercial vehicles (Euro 6), Verifying Real Driving Emissions, Official J. European Union, L 109, 2016.

[8] GUZZELLA, L., ONDER, C.H. Introduction to modeling and control of internal combustion engine systems. Springer. 2004.

[9] Worldwide emission standards. Passenger cars and light duty vehicles. Delphi. Innovation for the real world. 2016/2017.

Prof. Jerzy Merkisz, DSc., DEng. - Faculty of Transport Engineering, Poznan University of Technology.

e-mail: jerzy.merkisz@put.poznan.pl

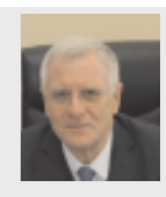

Prof. Jacek Pielecha, DSc., DEng. - Faculty of Transport Engineering, Poznan University of Technology.

e-mail: jacek.pielecha@put.poznan.pl 